\title{
Reason for Non-Evaluation
}

National Cancer Institute

\section{Source}

National Cancer Institute. Reason for Non-Evaluation. NCI Thesaurus. Code C53593.

The reason why the problematic device has not been evaluated by the manufacturer.

Examples include: device received in a condition which made analysis impossible, device not made by company, device problem already known, etc. 